\title{
Research in Environmental Education and Sustainable Development: an overview of publications in Brazilian journals of Qualis A2
}

\author{
Agnaldo Ronie Pezarini \\ Universidade Cruzeiro do Sul- UNICSUL- Brazil \\ rpezarini@gmail.com \\ Izilda Guedes Elias \\ Universidade Cruzeiro do Sul- UNICSUL- Brazil \\ izildaguedes@gmail.com \\ Profa. Dra. Carmem Lúcia Costa Amaral \\ Universidade Cruzeiro do Sul- UNICSUL- Brazil \\ carmem.amaral@cruzeirodosul.edu.br
}

\begin{abstract}
This article aims to present an overview of the research in Environmental Education and Sustainable Development in Brazil with four Qualis A2 journals as a locus. From the information obtained in the research locus was constructed a State of the Art and, later, the material obtained, an amount above forty-eight surveys, was analyzed in the light of Bardin. The analysis proceeded in the following categories: Year of publication; Institution of Higher Education; Empirical or Theoretical Work; Instrument of data collection; Area or discipline involved in the research; Objective of the Research; Achievement achieved with Environmental Education and/or Sustainable Development and Classification of work in EE and / or DS. The results obtained in the analysis indicate that the academic production for this subject has presented an increasing and that its discussions are based on multiple biases. We therefore point out the need to conduct studies, including to obtain more data, in order to better characterize the research carried out in the area of Environmental Education.
\end{abstract}

Keywords. Environmental Education, Sustainable development, Academic Production

\section{Introduction}

Man's concern about the environment has intensified since the 1960s, which was marked by political and economic protests and environmental-friendly movements. A milestone that contributed to this intention was the book SilentSpring, by researcher and biologist Rachel Carson, published in 1962, which explained how the unbridled use of pesticides such as DDT (dichloro-dichlorenil-tricloretane) could alter the cell processes of plants, and reduce small animal populations and endanger human health

For some authors such as Barros (2008), Carson was a pioneer of raising awareness of the interaction of men with the environment in which he lives. According to this author, the book served to create an awareness about the need to impose stricter and more protective 
legislation of the environment, waging a real war against industrial development causing immense environmental damage.

Another relevant fact was the emergence in 1968 of the "Clube de Roma", a small international group of professionals from various areas of industry, civil society who met, to discuss their concerns about the consumption of natural resources. From 1972, the report titled "The Limits of Growth", prepared by a team from the Massachusetts Institute of Technology (MIT), which became known as the Rome Club Report or Meadows Report is published, and dealt with problems for the future development of humanity.

The disclosure of the report quite alarmist causes concerns and protests of the population and in 1972, the United Nations (UN) held in Stockholm, the World Conference on Man and the Environment, which established principles for international environmental issues, including human rights, natural resource management, pollution prevention and relationship between environment and development.

During this conference, a document called the Declaration of the United Nations Conference on the Human Environment was conceived, with 19 principles for environmental issues. One describes that:

We have reached a point in history where we must shape our actions around the world, with greater attention to environmental consequences. Through ignorance or indifference we can cause massive and irreversible damage to the environment, on which our life and well-being depend. On the other hand, through greater knowledge and wiser actions, we can achieve a better life for us and for posterity, with an environment in tune with human needs and hopes. (t rechosof the Declaration of the UN Conference on the Environment - Stockholm, 1972, paragraph 6).

At the World Commission on Environment and Development (WCDD-1987), also known as the Brundtland Commission, was chaired by the Norwegian master in public health and former prime minister of Norway, Gro Haalen Brundtland, who was a preparatory process for the United Nations Conference (Rio-92), a report was developed that became known as "Our Common Future". This report contains information gathered by the commission over three years of research and analysis, highlighting social issues, especially land use, occupation, water supply, shelter and social, educational and health services, as well as urban growth management. In this report, one of the most widespread definitions of the concept is exposed: "sustainable development is that which meets the needs of the present without compromising the possibilities of future generations to meet their own needs". The Brundland report considers that widespread poverty is no longer inevitable and that the development of a city should focus on meeting the needs of the present without compromising the possibilities of future generations to meet their own needs".

The document "Our Common Future", after a 10-year evaluation of the Stockholm Conference, was aimed at a new look at development, a process that "[...] meet the needs of generations present, taking into account the needs of future generations" (COMMISSION, 1991, p. 46), emerging the concept of sustainable development, that is, represents an attempt to pass the idea of boosting the development of cleaner technologies, characterizing social responsibilities on the environmental damage caused.

In addition, Maurice Strong introduced the concept of eco-development, which was widely disseminated by Ignacy Sachs (1974), developing the five dimensions of ecodevelopment sustainability: social; economic; ecological; spatial; and cultural sustainability. 
Eco-development is the "endogenous development and dependent on its own forces, with the aim of responding to the problem of harmonization of social and economic development objectives with ecologically prudent management of resources and (Montibeller Filho, 1993, p.132).

According to Fonteles (2004), this conference resulted in several documents that, in short dialogue about actions that emphasize the real and urgent need to save the planet.

In the midst of so many acts aimed at protecting ecosystems, another that deserves attention is the United Nations Framework Convention on Climate Change and the Kyoto Protocol, where developed countries have committed themselves to adopting measures aimed at reducing greenhouse gas emissions. They should also submit periodic reports known as "National Communications" detailing their climate change policies and programs and presenting annual inventories of their greenhouse gas emissions. (Frangetto, 2002, p. 38)

At the 1972 Stockholm Conference there was concern for human life and natural resources, as well as animal species, i.e. environmental issues were based on air, soil, water and natural resource scarcity pollution endangering the well-being of man. Then comes the need for Environmental Education (EA) for the propagation of projects and programs.

The Intergovernmental Conference on Environmental Education of Tbilisi, held in 1977 in Georgia, organized by UNESCO in collaboration with UNEP (United Nations Environment Program), was a milestone for the definition and evolution of EA.

After all these years of environmental education, one has the idea of the richness of the project, but the environment, as Saúve (2005) reports, is not an object of study or a theme to be treated, is the plot of life itself, where health and culture are found and because it is a specific dimension of education, which is based on interactions personal and social and above all the relationship between the environment in which we live with the "sharedhouse of life", the planet.

We note that, despite the great diversity of concepts and opinions for the themes Environmental Education and Sustainable Development, the guiding bias of all concepts that are based in the light of several perspectives praises the concern with education aimed at citizen training and awareness of the individual as a living being integral to the same environment.

\section{Methodology}

This article aims to verify in the panorama and/or scenario of research on Argumentation in Science Teaching, what are the methodological tools of construction as well as the analytical tools used in the research from 2007 to 2017 . Therefore, it is based on methodological actions of the bibliographic survey and, in general terms, it is classified as a state of the art. It is necessary to justify that the realization and/or construction of this article based on the premises of the state of the art is in line with fiorentini's thinking (1993):

Only a small portion (of educators and researchers) has sought to verify what colleagues have already investigated about their theme or research problem. Some justify their practice by saying that the other works do not have the same theoretical framework or that they do not fall into the same line of research. Now, we do not consult and cite other works just to continue or to seek support for our ideas. We also do this to question or even refute your assumptions or their conclusions and referrals. (Fiorentini, 1993, p. 56)

It is in Ferreira (2002) that we praise the constituent actions of a state of the art or state of knowledge that are characterized as a bibliographic survey, the author characterizes this relationship between state of the art and bibliographic survey of the following Way: 
Defined as bibliographic in nature, they seem to bring in common the challenge of mapping and discussing a certain academic production in different fields of knowledge, trying to answer what aspects and dimensions have been highlighted and privileged in different times and places, in what forms and under what conditions certain master's dissertations, doctoral theses, publications in journals and communications in congress and seminar rooms have been produced. They are also recognized for performing an inventory and descriptive methodology of academic and scientific production on the theme that seeks to investigate, in the light of categories and facets that are characterized as such in each work and in all of them, under which the phenomenon is analyzed. (Ferreira, 2002, p. 258)

Based on the objective of identifying the analysis of what are the construction and analysis tools that govern research on Argumentation in Science Teaching, based on a bibliographic survey in the means of production and scientific dissemination that are included in the table 1, we build the state of the art. The search in the means of dissemination and or academic production was made by the descriptor Argumentation and, in continuity we performed the procedures that are contained in bardin's analysis (2006).

When it is intended to perform a content analysis in search of specific issues that express explicitness, systematization and expression of message content, Bardin (2006) points out that this action is possible to promote the analysis of content based on the premises cited in his work, this is possible from actions composed in three phases, being: a) pre-analysis; b) exploitation of the material and c) treatment of results, inference and interpretation.

According to Silva, et al (2017) in the light of Bardin (2006) the pre-analysis phase presents the peculiarities in his process and the documents should be analyzed according to criteria.

It comprises the realization of four processes: (i) floating reading (establishing data collection documents, the researcher becomes aware of the text, transcribes interviews); (ii) choice of documents (selection of what will be analyzed); (iii) formulation of hypotheses and objectives (provisional statements, which the researcher proposes to verify); (iv) preparation of indicators, through cutouts of texts in the documents analyzed, the themes that are most repeated may constitute the indices. (Silva et al, 2017, p. 171)

The realization of floating reading in search of specific data identified as categories, we select the research documents pertinent to the theme and, in possession of this selection, we promote clippings of them in order to compose the focus categories of this article. It is worth mentioning how important it is to act in the face of this phase of the process, as Bardin points out (2006)

At this stage, it is important to pay attention to the following criteria in document selection (Bardin, 2006): - Completeness: to try to exhaust all communication; - Representativeness: the selected documents must contain information representing the universe to be searched; • Homogeneity: the data should refer to the same theme; - Relevance: 
documents need to be consistent with the objectives of the research. (Silva et al, 2017, p. 171)

In general, the second phase, which refers to the exploration of the material, it aims at the exploration process for identification and construction of the categories of analysis. At this stage it is necessary to pay attention to these categories being constructed from an exclusivity criterion in order to promote the categorization of the constituent elements into a single parameter. In short, in the second phase of the prerogatives of bardin's analysis actions, we have to code so that one can classify with views and support of a categorization (BARDIN, 2006). To finalize the analysis process from Bardin's perspective (2006), it is necessary to stick to the prerogatives of how to act and act in front of the categorizations made in the second phase. In the light of Bardin (2006), Silva et al (2017), tells us that this process presents the following peculiarities:

The third and final stage consists in the treatment of results, inference and interpretation. In this stage, condensation and the highlight of information for analysis occurs, culminating in the inferential interpretations; is the moment of intuition, reflexive and critical analysis. (Silva et al, 2017, p. 172)

Thus, based on Bardin's perspective (2006), sequentially we dedicate ourselves to the second phase of the analysis process and, we establish as categories of analysis the following: Year of realization/publication; Higher Education Institution of Origin; Whether it is a Theoretical or Empirical research; Discipline and/or Area present in the research; Objective of The Research in EA and DS; The conquest of EA and/or DS through the research conducted. To contemplate the three phases of the process, we continued to perform the analysis and interpretation of the results from the descriptors and, to this end, we constructed graphs that express the information obtained for analysis and discussions

\section{Results and discussion}

The information obtained from the research Lócus generated an amount of research that immediately, from a floating reading we can classify it as fruitful in the sense that, they are diversified and managed to get answers to hypotheses, to give subsidies and, above all, to promote the conceptualization of the term Environmental Education and the practice of Sustainable Development. It is of utmost importance to identify that the results obtained in the research actions are far from the reality of the school and that the teachers have a deficient formation towards the themes, fitting, therefore, specific teaching formation. In order to clarify the methodological path presented in this research, we announce that the first procedure was to elect the research locus, and we affirm that we have opted to look for the articles in journals that have a Qualis of expressiveness, and in this case, we have opted for the Qualis A2 and, in view of the range of journals, we have adopted those in table 1.

Table 1 - Research Locus for identification of Surveys/Papers

\begin{tabular}{|l|c|}
\hline \multicolumn{2}{|c|}{ Research Locus } \\
\hline \multicolumn{2}{|c|}{ Description of the Research Locus } \\
\hline AMAZON - Journal of Science and Mathematics Education & 15 \\
\hline Essay Magazine Research in Science Education & 11 \\
\hline Journal Investigations in Science Teaching & 11 \\
\hline RECM Journal of Education, Sciences and Mathematics & 11 \\
\hline Total searches/articles & 48 \\
\hline
\end{tabular}


Source: table built by authors.

We present in the sequence the results of the mapping in front of the adopted categories, we emphasize from now on that the results are a priori classified as in fact delineator and reveal the specificities of the researches on Environmental Education and Sustainable Development.

\section{Year of realization/publication}

In a punctual and specific way we found higher research productivity on the themes EA and DS from 2013, as shown in graph 1, with this year a total production of ten articles published in the Research Locus. It is evident that scientific discussions and publications on the themes should be expanded and, even more in times when the world population praises consumerism and environmental degradation.

Figure 1 - Annual research productivity

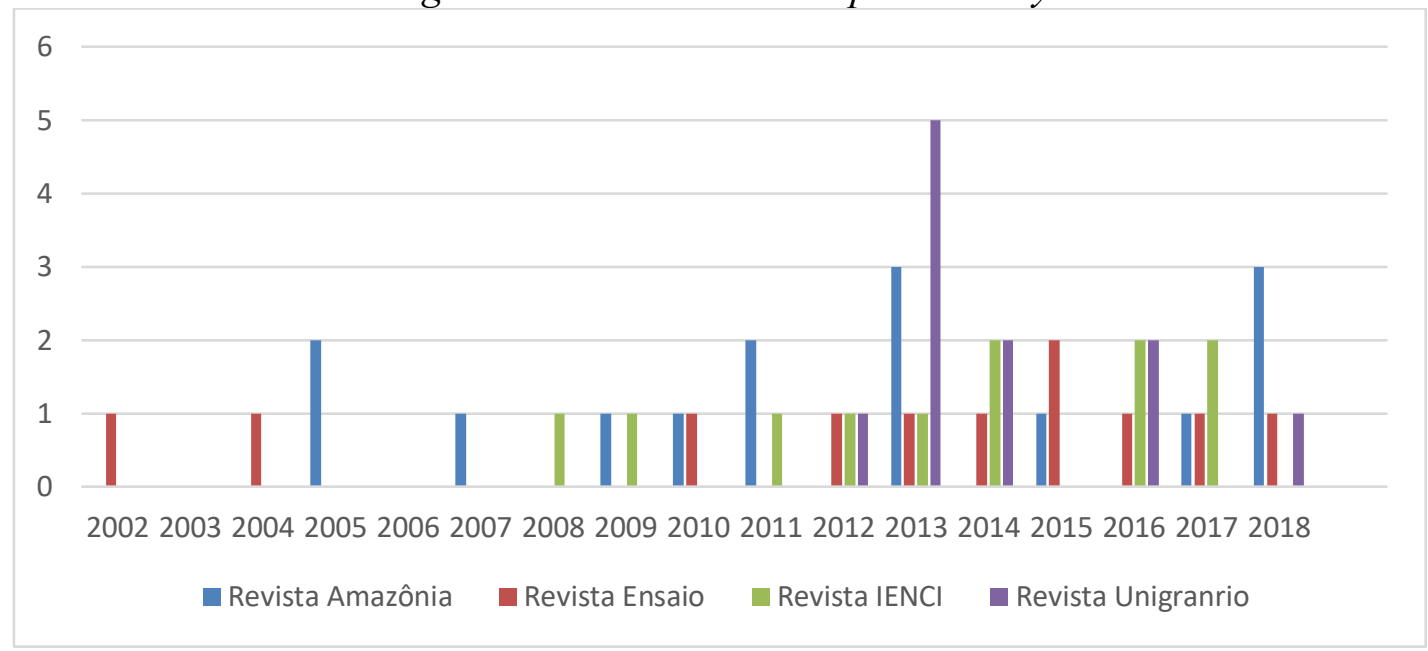

Source: Graph constructed by authors from the data obtained in the mapping

\section{Higher Education Institution of Origin}

Research on Environmental Education and Sustainable Development has been carried out in several educational institutions in our country, with a higher incidence of production in specific Higher Education institutions, as shown in graph II. We highlight the significant productivity in the institutions: Federal University of Pará (UFPA) followed by unigranrio University (UNIGRANRIO) and, relative productivity in other institutions. 
Figure 2 - Higher Education Institution of Origin of Research

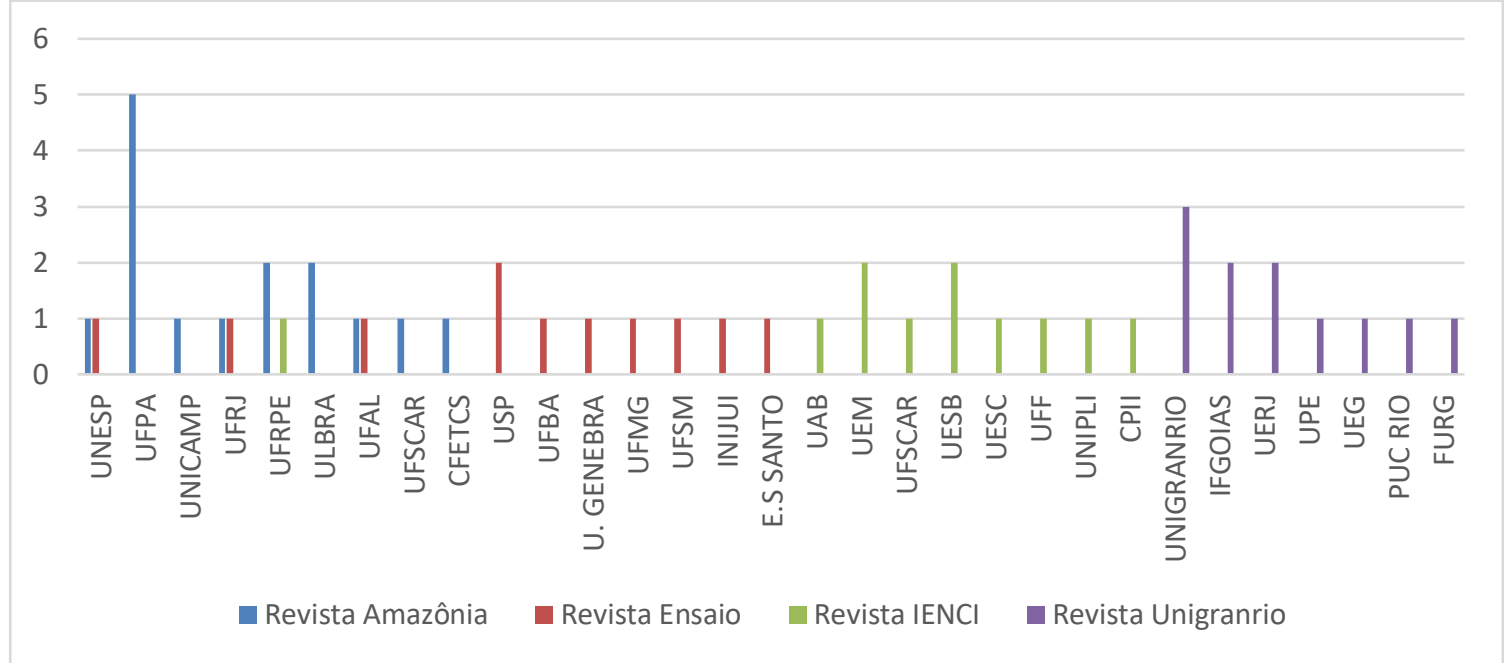

Source: Graph constructed by authors from the data obtained in the mapping

\section{Nature of Research, Theoretical or Empirical}

It is found that when the research refers to the themes of this mapping article, empirical research has the most frequent type research. This data is in line with the objectives of research of this nature because, the research we find dialogues mostly of processes of awareness building, the construction of concept and practice and/or action that promotes Environmental Education and Sustainable Development.

Figure 3 - Article on Theoretical or Empirical Research

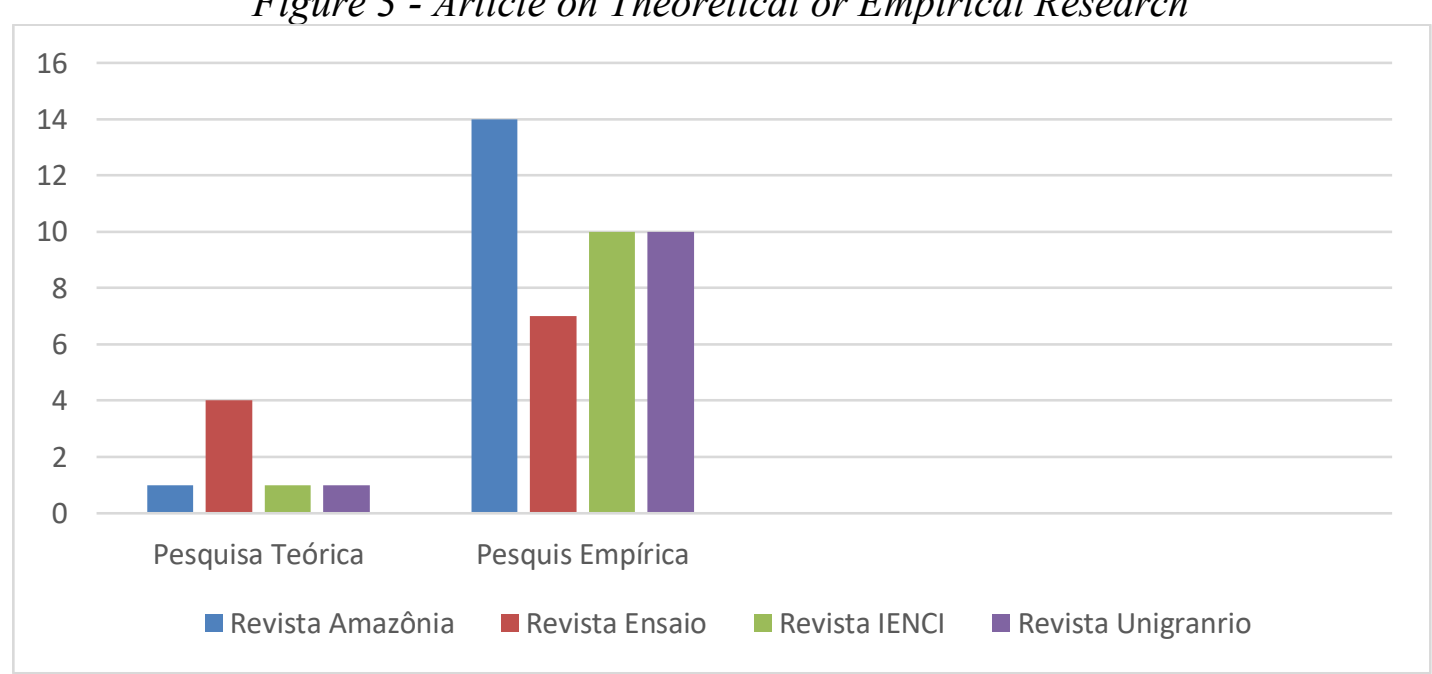

Source: Graph constructed by authors from the data obtained in the mapping

\section{Discipline and/or Area present in the research}

Academic scientific production in our country is dispersed in the numerous educational institutions. The survey from the descriptors EA and DS in the journals focus of this mapping reveal that the diversity of areas acting from the perspective of a training aimed at a citizen conscious towards the environment and its preservation, we find that it is the discipline sciences that had the greatest presence in research activities, followed by Chemistry, Biology and 
Pedagogy. In the case of Pedagogy, the research deals with teacher education on the topics of this article.

Graph 4 - Specific area and/or discipline active in the research

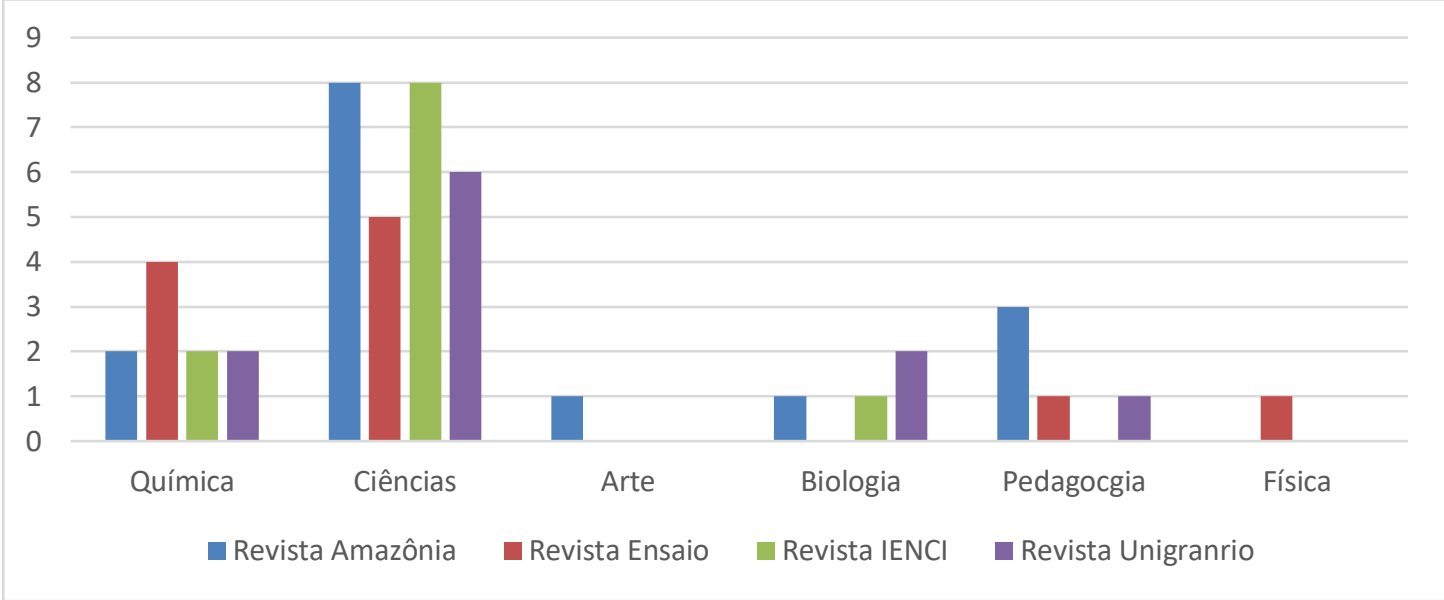

Source: Graph constructed by authors from the data obtained in the mapping

\section{Data collection instrument and/or research methodology}

The mapping showed that the most frequent data collection instrument in the focus surveys of this article is the interview followed by the questionnaire, as shown in graph 5, from which the researchers obtain information about the central objectives of their research, which in turn brings as the most frequent methodology the Case Study and Research that involves the construction and application of Didactic Sequences. We identified that there is considerable productivity of State of The Art research in which the Bibliographic Survey is in evidence.

Graph 5 - Data collection instrument and/or research methodology

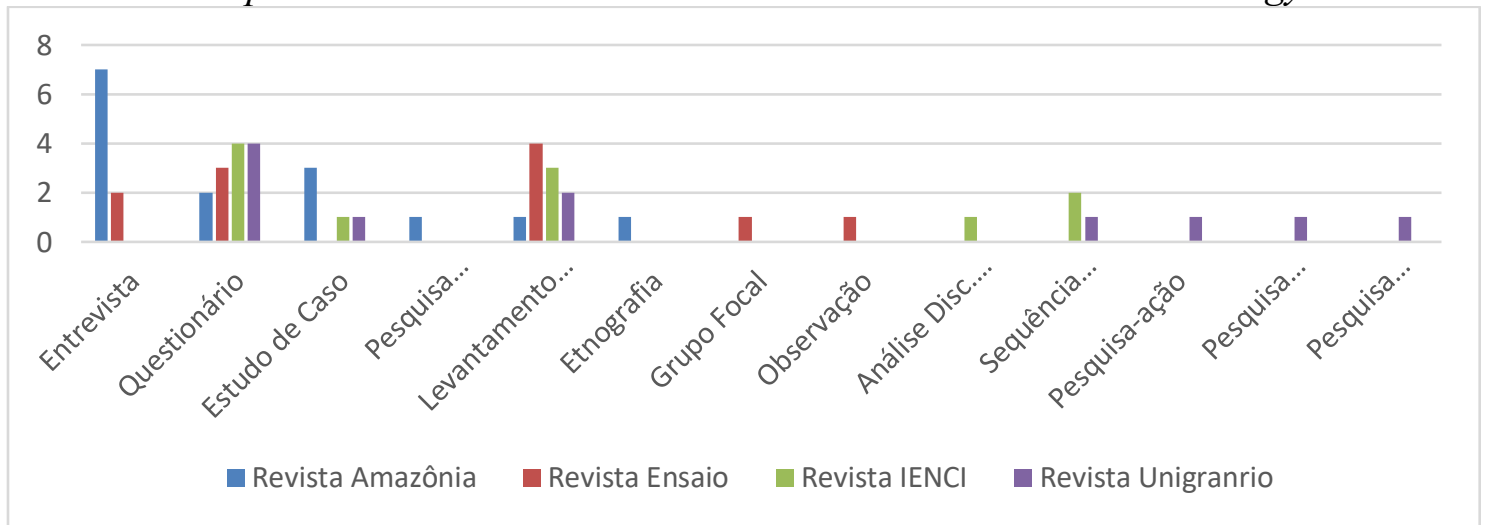

Source: Graph constructed by authors from the data obtained in the mapping

\section{Configuration of Research on the Axes of Environmental Education and Sustainable Development}

We sought in the mapping to identify the production of EA and SD, in this case, we found that Environmental Education is the focus of most evidence in research related to the Environment, as shown in Graph 6. 
Figure 6 - Distinction of EA and/or DS Search

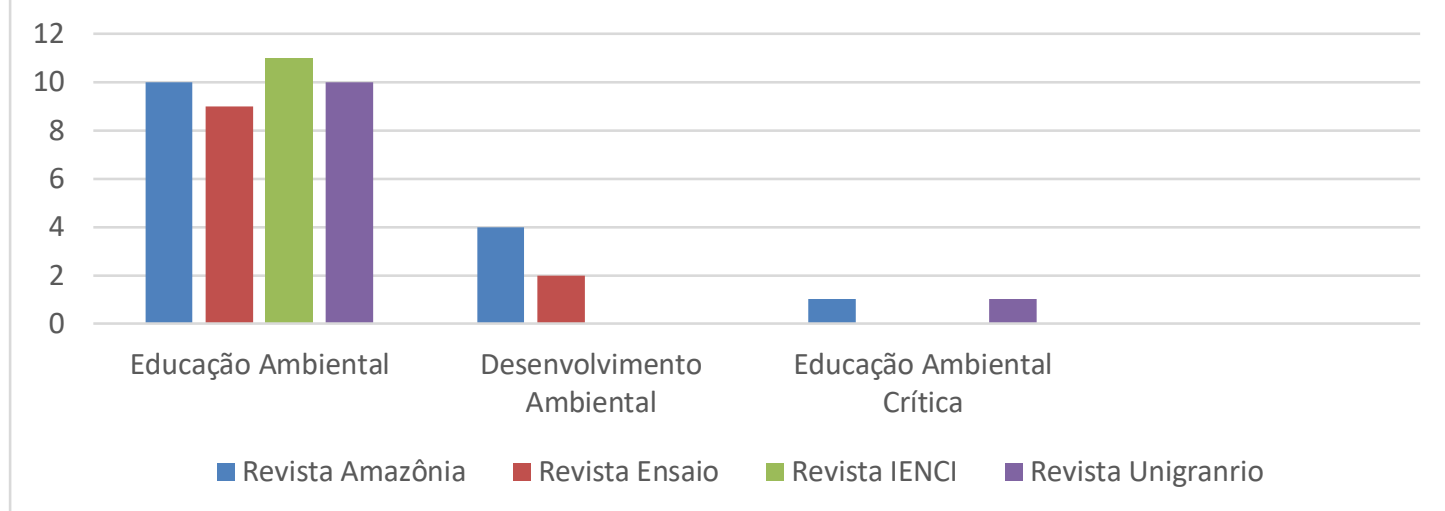

Source: Graph constructed by authors from the data obtained in the mapping

As Critical Environmental Education appears as the objective of research itis necessary to present its specificities, so inthis sense, according to Loureiro (2007), the main brand of critical environmental education:

it is in stating that, because it is a social practice like everything that refers to human creation in history, environmental education needs to link ecological processes to social people in world reading, in the way of intervening in reality and existing in nature. (Loureiro, 2007, p.66)

The criticality in question must be in line with the environmental crisis promoted by the action of man and try to promote a paradigm shift, as presented by Leff (2002)

The environmental crisis is the crisis of our time. [...] This crisis presents itself to us as a limit on the real that resigns and reorients the course of history: limit of economic and population growth; limit on ecological imbalances and life-sustaining capacities; poverty and social inequality. (Leff, 2002, p. 191).

Objective of Research in Environmental Education and Sustainable Development

This category was certainly the one that, in our conception and perspective, shows how much Environmental Education and Sustainable Development present diversity of biases, since there are multiple objectives listed when a research on EE and SD is carried out. We identified a predominance of objectives that resort to various pedagogical practices, as shown in Graph 6, actions and/or subsidies that can promote environmental education and SD, we lauded as an action to relate pedagogical practices with environmental education and SD, the actions in which they promote discussions and/or focus their actions on practices such as: Discussion of Transgeny; Use of films as Avatar in the construction of the conception of EE; The use of Horta as a means of promoting EE; The use of conceptual maps for the promotion and construction of environmental thinking; The Green Chemistry as a conductor of EE; The issues CTSA as a strand of EE; The use of trails for the promotion of the ideology of EE; The use of the discipline of Art for awareness; The psychology and its relationship with EE; The discussions about water and about pesticides as a means of promoting awareness of EA and SD. 


\section{(10) TECHNIUM}

Figure 7 - Research Objective

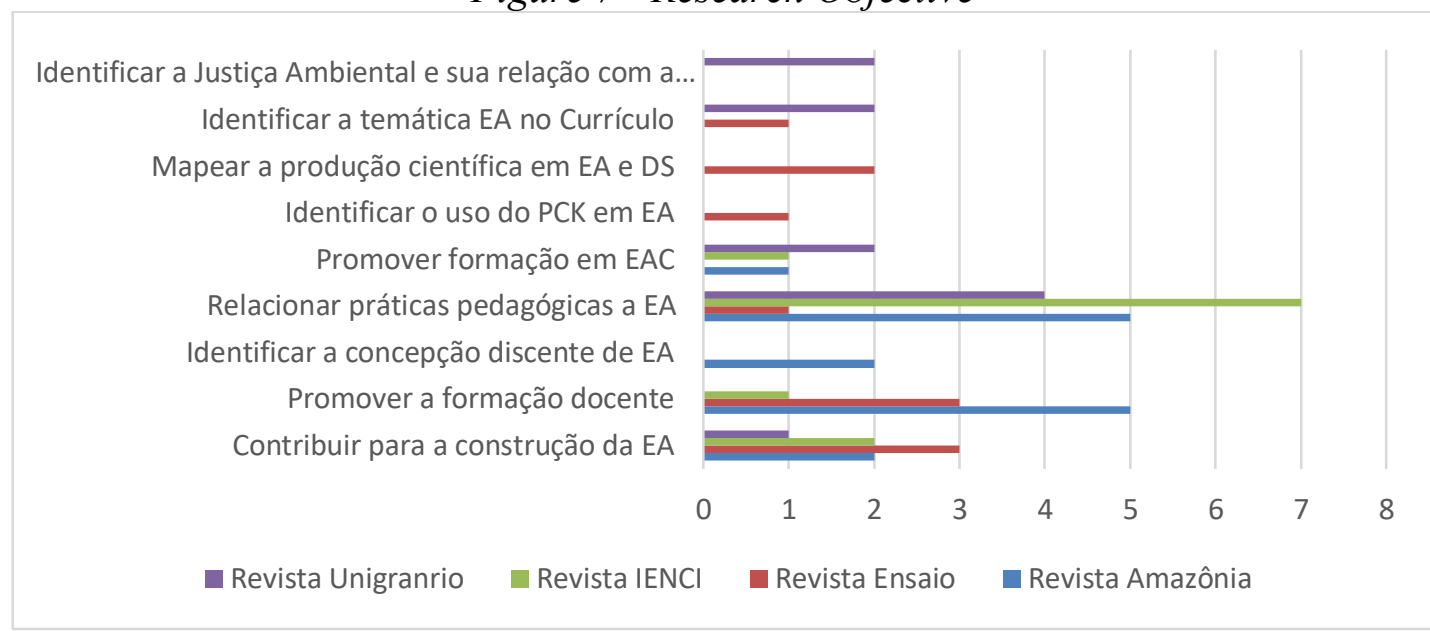

Source: Graph constructed by authors from the data obtained in the mapping

In order to discuss the specificities of such pedagogical practices for the promotion of AS, we present the specificities of the practices and/or relationships between the various actions for the benefit of The and DS.

The transgenic theme was evidenced as a proposal for the promotion of AS, in this sense when it is outlined as an objective of research in AS, it is evidenced by researchers that, the research does not present subsidies on transgenics to teachers working in schools as reported Da Rocha \& Slonski (2015):

We emphasize that the selection of the analyzed articles refers to journals of an academic nature and destined to the teaching public. However, the work on transgenics are still primarily in studies aimed at researchers and not teachers. Perhaps this is why few studies conceptualized transgenics with a certain depth and, at some point, indicated teaching strategies on the theme in EC. It is worth remembering, as Delizoicov (2004; 2005) points out, that it is necessary to treat with caution the criticism stemming from the problem of the little return of EC research results to the classroom. This is because the researcher is subject to a complex educational context, on which he has no control over the use of his research. In addition, the impact of research results on EC on educational practices, within the school, is quite differentiated and does not have a single reference pattern (Da Rocha \& Slonski, 2015, p.88)

Another objective of the research was to promote social representation and its relationship with THE, According to Jodelet (2001, p. 22), social representation is [...] a form of knowledge, socially elaborated and shared, with a practical objective, and which contributes to the construction of a reality common to a social set. Also designated as knowing common sense or even knowing naïve, natural, this form of knowledge is differentiated, among others, from scientific knowledge. More specifically, Ethnoictiology, which studies the knowledge, classification and use of fish by human groups (Marques, 1991; 1995; 2001) has been investigated by the nupélia environmental educatorgroup. Popular knowledge of local fishermen results from a longer and more constant 
contact with their natural resources, because fishing communities understand (what we researchers call) the ecology and behavior of fish, aiming at performance of artisanal fishing strategies. From a perspective of conservation of the natural and cultural environment of the floodplain of the Parana River, it is visible the importance of valuing and redeeming the knowledge that fishermen bring from their experiences and experiences, bringing them into the school, space of socialization of knowledge. In addition, school and teacher should not ignore the diversity of cultures existing in society and therefore need to find ways to include and dialogue with the different knowledge belonging to students, because we live in a country that houses rich and ethnic groups; denying or rejecting them is a disregard for both these different ways of knowing and by the students themselves (Da Riva et al, 2014, p. 345).

A recent theme in research on EA and SD is Green Chemistry, in this sense when it was present as a research objective, its conceptual bias was focused on environmental awareness research in industrial environments and thus conceptualizing Green Chemistry is necessary and, in this sense, we resort to Brandão et al (2018)

the term Green Chemistry (QoL) or Sustainable Chemistry, was coined and perceived as actions that pondered the processes to be followed by the chemical industry. The priority would be to analyse existing chemical routes by reducing or even eliminating them in order to generate a minimum of waste, thereby stimulating green technological innovations. (Brandão et al, 2018, p. 61)

\section{The conquest of EA and/or DS through the research conducted}

The following category expresses the conquest of the research done in Environmental Education and Sustainable Development, an item of great importance for revealing the results of these researches as well as its relation between research and reality in favor of a bigger conquest, the environment in its stability and harmony. The results reveal that, when it is proposed to conduct research aimed at EE and / or Sustainable Development there are positive results when it is appealed to and enjoy the same distinct pedagogical practices that promote harmony and positivity between the supporting theme (Green Chemistry, CTSA, Agrotoxics, Environmental Justice, Social Representation etc.) and the protagonist themes of EA and SD. 
Graph 8 - The achievement of EA and/or DS through the research carried out

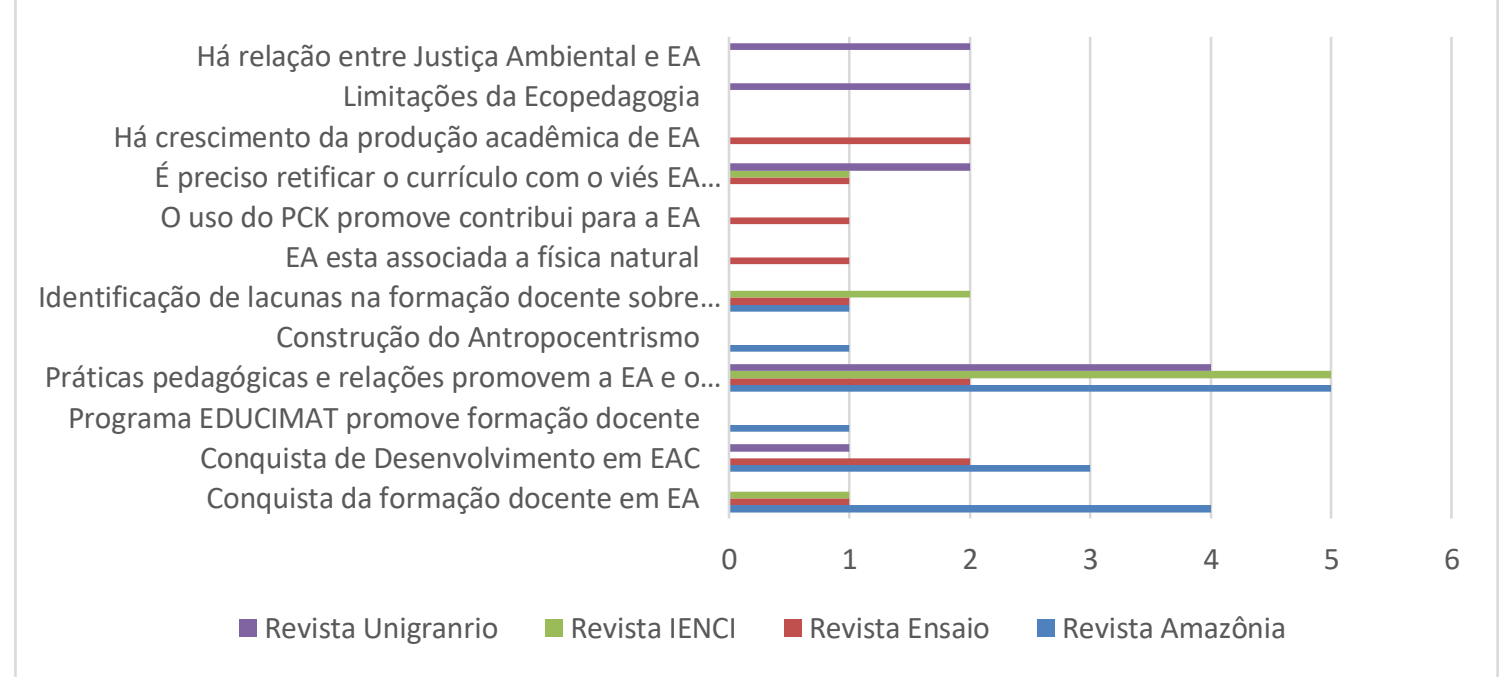

Source: Graph constructed by authors from the data obtained in the mapping

Environmental justice had been an achievement according to research conducted in EA and DS, in this sense, we emphasize that environmental justice seeks an articulation between the principles of justice and ecology, having in principle the idea that the roots of environmental degradation and social inequality are the same as those found in the mode of capitalist production, especially when the process of alienation of work begins (ACSELRAD, 2001). According to Marx, quoted by Novicki (2007), the concept of alienated work involves four main dimensions: v. 1st - man is alienated from nature, strangeness of the thing, despite transforming it daily through work and being at the same time, transformed by it and by the work that measures this relationship, does not realize it; v.2nd - man is alienated from himself, of his own vital activity, of work, self-strangeness; v.3 - man is alienated from his generic being, of his being as a member of the human species, of the human race, not realizing that he belongs to a totality that lives in conditions similar to his; v. 4th - man is alienated from man, of other men and is not aware of his midst.

idea that the fight for environmental justice should be based on a set of principles and practices that: $a$-ensure that no social group, whether ethnic, racial or class, supports a disproportionate portion of the negative environmental consequences of economic operations, policy decisions and federal, state, local policies, as well as the absence or omission of such policies; $b$ - ensure fair and equitable, direct and indirect access to the country's environmental resources; $c$ - ensure broad access to relevant information on the use of environmental resources and the allocation of tailings and location of sources of environmental risks, as well as democratic and participatory processes in the definition of policies, plans, programmes and projects concerning them; $d$-favor the constitution of collective subjects of rights, social movements and popular organizations to be protagonists in the construction of alternative models of development, which ensure the democratization of access to environmental resources and the sustainability of their use. (Puggian et al, 2014, p. 2)

We noticed that in view of the application and experience of green chemistry issues, equity and coherence is possible with discussions for environmental awareness. 
Another aspect present in the achievements of research on EE in particular is the promotion and construction of a critical environmental education, which according to TozoniReis refers to:

From the perspective of critical, transformative and emancipatory environmental education, environmental themes cannot be curricular content in the sense that traditional pedagogy treats teaching content: pre-established knowledge that should be transmitted from those who know (the educator) to those who do not know (the student). Critical and transformative education requires a more vivid and dynamic treatment of appropriate knowledge, constructed, dynamically, collectively, cooperative, continuous, interdisciplinary, democratic and participatory, because only in this way can contribute for the process of raising awareness of the subjects for an emancipatory social practice, a condition for the construction of sustainable societies. (Tozoni-Reis, 2006, p.97)

Out of great surprise to identify that THE issues are also rooted in biopsychological aspects, with evidence of the Cinestésico-corporal and Visuo-spatial aspects, in this sense, we evidence that the issues of ACHIEVEMENTs of A can be spontaneously expressed through psychology and/or Biopsychological aspects in their intelligences, as Gardner brings to the light of Nicollier \& Velasco in table 2

Table 2 -The Biopsychological Aspects and gardner's Eight (8) Intelligences

\begin{tabular}{|c|c|}
\hline Intelligences & \\
\hline $\begin{array}{l}\text { Cinestésico- } \\
\text { corporal }\end{array}$ & $\begin{array}{l}\text { Refers to the use of the body to express ideas and feelings; to the use of } \\
\text { hands to transform the medium, including specific physical skills such as } \\
\text { broad and fine motor coordination, balance, dexterity, strength, } \\
\text { flexibility, speed and proprioceptive, tactile and skilled capabilities. }\end{array}$ \\
\hline Visuo-space & $\begin{array}{l}\text { Refers to sensitivity to color, shape, line, configuration, and space and } \\
\text { the relationships between these elements. Includes viewing capability, } \\
\text { graphical representation of ideas, and orientation in a spatial matrix. } \\
\text { Allows the person to perceive the external and internal images, that is, } \\
\text { the visuo-spatial world, recreate, transform and modify images. }\end{array}$ \\
\hline Naturalist & $\begin{array}{l}\text { It consists of the ability to recognize patterns in nature, identify and } \\
\text { classify objects and the numerous species, understand natural systems } \\
\text { and those created by man. It includes sensitivity to natural phenomena } \\
\text { such as clouds, mountains and landscapes. }\end{array}$ \\
\hline Interpersonal & $\begin{array}{l}\text { It consists of the ability to understand others and interact effectively with } \\
\text { them. It stems from the sensitivity to distinguish mood, intentions, } \\
\text { motivations and feelings in others and react appropriately to them. It may } \\
\text { include the ability to interpret facial expressions, voice, and gestures and } \\
\text { discriminate interpersonal signals and the ability to respond to these } \\
\text { signals pragmatically. }\end{array}$ \\
\hline Intrapessoal & $\begin{array}{l}\text { It refers to self-knowledge and the ability to act adaptably on the basis of } \\
\text { this. Includes the ability to build an accurate image of yourself and the } \\
\text { ability to use this knowledge for the planning and direction of your life. } \\
\text { Includes self-discipline, self-understanding and self-esteem. }\end{array}$ \\
\hline
\end{tabular}




\begin{tabular}{|l|l|}
\hline Linguistic & $\begin{array}{l}\text { It consists of the ability to think of words and use oral and written } \\
\text { language. Includes the ability to explore the syntax, semantics, and } \\
\text { pragmatic dimensions of language, explanation, interpretation, and } \\
\text { metalanguage. }\end{array}$ \\
\hline $\begin{array}{l}\text { Logical- } \\
\text { mathematics }\end{array}$ & $\begin{array}{l}\text { It consists of the ability to use numbers and reason logically. It refers to } \\
\text { the ability to calculate, quantify, consider propositions and hypotheses } \\
\text { and perform complex mathematical operations. The types of processes } \\
\text { related to this intelligence are: categorization, classification, inference, } \\
\text { generalization, calculation and hypothesis testing. }\end{array}$ \\
\hline Musical & $\begin{array}{l}\text { It refers to the ability to perceive, discriminate, transform and express } \\
\text { musical forms. It consists of sensitivity to intonation, melody, rhythm } \\
\text { and tone. }\end{array}$ \\
\hline
\end{tabular}

Cast: Nicollier and Velasco, 2009, p. 425)

The so-called Naturalist Intelligence was also an achievement included by researchers in their work and, in this case, we bring their specificities according to Nicollier \& Velasco (2009), Naturalistic Intelligence is described by Gardner (1999), as the ability to recognize patterns in nature; identify and classify objects and numerous species; understand natural systems and those created by man. It refers to sensitivity to other natural phenomena, such as clouds, mountains and landscapes. Like the other intelligences, Naturalistic Intelligence meets the scientific criteria that define them, possessing a distinct developmental history and a definable set of specialized performances, called the final or adult state (Gardner, 1999). The expression of his adult role is represented by the naturalist who plays an important role in all cultures. The naturalist demonstrates great experience in the recognition and classification of numerous speciesflora and fauna - of their environment, and societies appreciate people capable of recognizing especially valuable or remarkably dangerous members of a species and categorizing new and unknown organisms. (Nicollier; Velasco, 2009, p. 432)

Anthropocentrism is also an achievement of the focus research of this article, its description is beyond conceptualizing, but rather leads to a healthy discussion about the citizen's attitude towards degradation and environmental issues. In this sense, Loureiro (2004) talks on this issue as follows: It is necessary to mention anthropocentrism with a little more analytical concrete. It is insufficient to keep saying that the responsibility of degradation is anthropocentric attitude. It has its own qualities in contemporary societies that are defined by hierarchical relations of power, subject-object dichotomy, cultural prejudices and class inequality.

Based on principles of a formation that considers everyday life ecopedagogy translates into a healthy action in the process of citizen formation, alasing issues of environmental preservation and, being beyond the frontier of the traditionality of education, in this sense Gutierrez and Prado dialogue pointed out these considerations:

point out that Ecopedagogy is an organic pedagogy, which embraces the common life in new ecological-social referents and pedagogical spaces, enabling educational processes to be conducted from a perspective of sustainability and construction of necessary planetary citizenship. More than a theoretical reconfiguration, it is the 
proposition of principles and pedagogical paths that have pedagogical mediation and learning conceived from everyday life. (Gutierrez; Prado, 2013, p. 65)

In addition to a pedagogy focused and based on specific issues of citizen education and concern for the environment, it is up to the question that how the school should act in this case? It is a fact that all the action of daily school is based on documents re regiment such as PCN and Guidelines, in this case, the PCN must according to one of the achievements of the analyzed research be present and focus on a Critical Environmental Education that requires the interdisciplinarity for the formation of a conscious citizen, as Pereira, Da Fontoura, De La Rocque (2013)

Through the discussion carried out in this article we conclude that the $N P c s$ approach the environmental theme within an Perspective of EAC, proposing an interdisciplinary, contextualized and critical teaching work seeking learning with meaning and that form a citizen aware of their responsibilities vis-at the environment and society, aiming at an education where the student is active and questioning. Throughout the document we observe a proposal of continuous and permanent EA, linked to the student's world, their knowledge, feelings and perceptions, their experiences and the environment in which it is inserted (their community, their neighborhood, their city), encouraging them to a reflection of local and global problems within a context of environmental and social (and duties) justice and equal rights. (Pereira; Da Fontoura; De La Rocque, 2013, p, 141)

The practice of the school garden was shown in the research analyzed a healthy action in the process of conquering the acquisition and development of the premises of Environmental Education, because it brings in practice the action and construction of awareness, in this sense. In view of the above, Morgado and Santos (2008) states that:

The vegetable garden inserted in the school environment can be a living laboratory that enables the development of various pedagogical activities in environmental and food education by uniting theory and practice in a contextualized way, assisting in the process of learning and strengthening relationships through the promotion of collective and cooperative work between the social agents involved (Morgado; Santos, 2008, p.9).

Highlighting theoretical issues is a very important action in the construction of knowledge, even more so with the issues of THE, in this sense the vegetable garden in the school environment is an achievement that must be present in all school units in this country in a way promote a theoretical-practical action in students in the process of training.

Not far from the reality of promoting a training, the vegetable garden in school can promote this action, however, the training and awareness of the industry in the face of its gigantic share of diseases in the environment is mandatory and urgent promotes the necessary discussion for coherent training towards environmental issues in the industrial environment.

In order to elucidate what green chemistry is about and because it has been pointed out as one of the achievements of the research analyzed in this mapping will discuss some of its specificities. Química Verde,For the movement related to environmental issues by the high consome of petroleum derivatives by developed countries, concerns about the high levels of $\mathrm{CO}_{2}$ concentration in the atmosphere, climate change and irreparable damage to society. These movements, of course, concerns arise about Chemistry in the use and manipulation of consumer 
and packaging products and the use of fosseis fuels, final deposition of industrial waste and agriculture by the use of pesticides harmful to man and the environment.

"Green chemistry" or "sustainable chemistry," according to Veiga (2012) focuses on the development of clean methods that prevent waste formation, which is more advantageous than developing new technologies to treat them.". (VEIGA, et al., 2012).

Green Chemistry is based on twelve principles guided by concern about quality of life, sustainable development and environmental preservation, listed below:

1.Prevention of waste formation: avoiding the formation of toxic product; 2. Atomic efficiency: incorporate as many atoms as possible from the reagents into the final product; 3. Safe synthesis: synthetic methodologies that use and generate substances with little or no toxicity to human health and the environment; 4. Development of Safe Products: products that do not cause harm to the environment; 5 . Use of Safe Solvents and Auxiliaries: use of innocuous or easily reusable auxiliary substances such as solvents, purification agents and drying; 6. Search for Energy Efficiency: development of processes that occur at room temperature and pressure; 7. Use of Renewable Raw Material Sources: use of biomass as raw material should be prioritized; 8. Avoid The Formation of Derivatives: avoid processes involving intermediaries with blocking groups, protection/deprotection, or any temporary modification of the molecule; 9. Catalysis (Selectivity): replacing stechiometric reagents; 10. Degradable products: biocompatibility; should not remain in the environment, degrading in innocuous products; 11. Real-Time analysis for pollution prevention: possibility of formation of toxic substances should be detected before its generation; 12. Intrinsically Safe Chemistry for Accident Prevention: minimising the risk of accidents such as leaks, fires and explosions (Anastas, P. T.; Warner, J, 1998)

Martin Polia Kof and Paul Anastas claim "The twelve principles are so obvious that the chemicals of the future will wonder why it took so long to integrate them into the core of chemistry," "Why produce chemicals costly and in a wasteful way if we can produce in a clean and cheap way?" In the principles among other aspects, there is the reduction of waste generation, the atomic and energy economy, and the use of renewable raw materials. The use of renewable raw materials is a strategic issue for Brazil, because it is one of the main biomass producing countries and, consequently, one of the largest generators of agro-industrial waste that can serve as abundant and inexpensive raw material for the processes of chemistry transformation.

\section{Final Considerations}

The study reveals that Environmental Education and Sustainable Development are a theme of great importance for the scientific community given the amount of research produced and by the discussions that the works/articles and research promote, since the research has not been routine and constant frequency, but rather there is a list of diversity of objectives, actions and results obtained from classroom practices. Generally speaking, research is also distributed among the HEIs, to the disciplines of focus of nature science.

It is of salutary importance to identify in the research on the themes of this mapping are in addition to promoting the construction of simple awareness, they by aggregating and relating differential practices such as the discussion of Green Chemistry, Transgenia, Horta, CTSA 
issues, Biopsychology, etc., promote the development decision-making process and favoring scientific knowledge.

We also identified a substantial production in the face of research that works in the construction of EA and DS, although the models are biased, which brings us the need for research that can diversify this process.

We emphasize that there is little academic productivity towards the theme that is so necessary and, above all these should be focused so that they can be reproduced in the school environment and are not only in the academic environment.

\section{References}

[1] ACSELRAD, H. The duration of cities:sustainability and risk in urban policies. Rio de Janeiro: DP\&A, 2001.

[2] BARDIN, L. Content analysis. Lisbon: Editions 70, 2006

[3] BARCHI, R. "Inverse" contributions, "perverse" and smaller to environmental educations. Interactions, no 11, p. 1-19, 2009.

[4] Brazil. National Curriculum Parameters: Environment and Health. Ministry of Education. Secretariat of Fundamental Education. 2 ed. Brasília, 2000.

[5] BRANDÃO, Juliana Barreto et al. Mapping of publications on the teaching of green chemistry in Brazil from social networks. Amazon: Journal of Science and Mathematics Education,v. 14, n. 30, p. 59-76, 2018.

[6] BARROS, Wellington Pacheco. Environmental lawcourse. 2. ed. São Paulo: Atlas, 2008. p. 06.

[7] CMMAD - World Commission on Environment and Development. Our common future. 2nd ed. Translation of Our common future. 1st ed. 1988. Rio de Janeiro : Editor of the Getúlio Vargas Foundation, 1991

[8] DA ROCHA, André Luís Franco; SLONSKI, Gladis Teresinha. A look at transgenics in the areas of research in science teaching and environmental education: contributions to the training of teachers. Investigations in Science Teaching,v. 21, n. 3, p. 74-91, 2016.

[9] DA RIVA, Poliana Barbosa; OBARA, Ana Tiyomi; SUZUKI, Harumi Irene. Ethnosaberes about fish by fishermen and teachers of the flood plain of the upper Paraná River. Investigations in Science Teaching,v. 19, n. 2, p. 343-361, 2016.

[10] DE SOUZA, Dolores Albino et al. ENVIRONMENTAL EDUCATION IN ELEMENTARY SCHOOL I: THE CONSTRUCTION OF A CURRICULAR PROPOSAL FROM THE CTSA APPROACH (SCIENCE, TECHNOLOGY, SOCIETY AND ENVIRONMENT). Journal of Education, Sciences and Mathematics, v. 8, n. 1, 2018.

[11] DIAS, Genebaldo Freire. Environmental Education: principles and practices. 9. ed. São Paulo: Gaia, 2004.

[12] FRANGETTO, Flavia W.; GAZANI, Flavio R. Feasibilization of the Clean Development Mechanism (CDM) in Brazil. Editora Fundação de Peirópolis, 2002.

[13] FERREIRA, N.S. de A. Research called 'state of the art'. Education \& Society,year 23, p. 257-272, Aug. 2002.

[14] FIORENTINI, D. Memória and analysis of academic research in Mathematics Education in Brazil: the CEMPEM/FE-Unicamp thesis bank. Zetetiké , v 1, n.1, p.5576, sea. 1993.

[15] FONTELES, Cláudio Lemos. Abortion: fetus with anencephaly. Consulex: Legal Journal, São Paulo, v. 8, n. 184, p. 46-49, September 2004 
[16] GUIMARÃES, M. Critical Environmental Education. In: LAYRARGUES, P.P. (Coord.). (2004). Identities of Brazilian Environmental Education. Ministry of the Environment. Environmental Education Board. Brasilia.

[17] GUTIÉRREZ, Francisco; PRADO, Cruz. Ecopedagogy and planetary citizenship. 3rd ed. Trad. Sandra Tabucco Valenzuela. São Paulo: Cortez, 2013.

[18] JARA, C. J. The Sustainability of local development: challenges of a process under construction. Brasília: IICA; Recife: Seplan, 1998.

[19] Jacobi. P. (2003). Environmental Education, Citizenship and Sustainability. Research Notebooks, n. 118, pp.189-205.

[20] JODELET, D. (2001). Social representations: an expanding domain. In D. Jodelet (org.) Social representations (pp. 17-44). Rio de Janeiro: EdUerj.

[21] KOFF, Elionora Delwing( The environmental issue and the study of Sciences: some activities. Goiânia: UFG, 1995.

[22] LAYRARGUES, P. P.; LIMA, G.F.C. The political-pedagogical macrotrends of Brazilian environmental education. Environment \& Society, São Paulo, v. 17, n. 1, p. $23-40,2014$.

[23] LATINI, Rose Mary; FROM CONCEIÇÃO SOUSA, Adryana. Chemistry and Environment Teaching: the joints present in the New Chemical Journal at School (QNEsc). Investigations in Science Teaching,v. 16, n. 1, p. 143-159, 2016.

[24] MARCATTO, Celso. Environmental education: concepts and principles. 1. Ed. Belo Horizonte: FEAM, 2002.

[25] MEDINA, N. M. (2002). Multipliers training for Environmental Education. In A. G. Pedrini (Org.) The Social Contract of Science, uniting knowledge in Environmental Education. (pp. 47-70). Petrópolis: Voices.

[26] MONTIBELLER FILHO, Gilberto. The myth of sustainable development: environment and social costs in the modern system of producer of goods. 2nd ed. Florianópolis: Ed. da UFSC, 2004.

[27] MORGADO, F. S.; SANTOS, M. A. A.A.A. A school garden in environmental and food education: experience of the Horta Viva Project in the municipal schools of Florianópolis. Electronic ExtensionMagazine, 5(6): 1-10, 2008.

[28] NICOLLIER, Valerie; VELASCO, Fermin Garcia C. To know the Atlantic forest in childhood: a contribution of the theory of multiple intelligences to environmental education. Investigations in Science Teaching, v. 14, n. 3, p. 421-456, 2016.

[29] NOVICKI, V. Práxis: problematizing awareness and participation in Brazilian environmental education. In: LOUREIRO, C.F. (org). The environmental issue in critical thinking: nature, work and education. Rio de Janeiro, 2007.

[30] PUGGIAN, Cleonice; DAS FLORES VICTER, Eline; FREITAS, Adriano Vargas. ENVIRONMENTAL JUSTICE, RACIAL EQUALITY AND EDUCATION: CROSSSECTIONAL DIALOGUES. Journal of Education, Sciences and Mathematics, v. 3, n. 3, 2014.

[31] REIGOTA, Mark. What is environmental education. 2. ed. São Paulo: Brasiliense, 2009.

[32] RIBERAYGUA, Marta Fonolleda; FABRÍCIO, Tárcio Minto; DE FREITAS, Denise. La gestión del agua en un município: una oportunidad para conectar la escuela, la ciudad y el mundo. Investigations in Science Teaching, v. 22, n. 2, p. 154, 2017.

[33] RODRIGUES, A. R. F; LABURU, C. E. Environmental Education in biology teaching and a look at the forms of relationship between humans and animals. Brazilian Journal of Research in Science Education, v. 14, n. 2, p. 171 - 184, 2014. 
[34] SATO, M. (2003). Environmental Education. Rhyme. São Carlos, SP.

[35] SAUVÉ, LUCIE. Environmental Education: possibilities and limitations. Montreal. Education and Research, São Paulo, v. 31, n. 2, p. 317-322, May/Aug. 2005

[36] SILVA, A.H. et al. Content analysis: do we do what we say? A survey of studies that claim to adopt the technique. InteractiveKnowledge, v. 11, n. 1, p. 168-184, 2017.

[37] TRAVASSOS, Edson Gomes. The practice of environmental education in schools. 2. ed. Porto Alegre: Mediation, 2006. 